\title{
SERGIO BUARQUE DE HOLANDA E A HISTORIOGRAFIA PAULISTA
}

Walkiria Costa Fucilli C'hassot ${ }^{1}$

RESUMO: O ensaio tece reflexões acerca da historiografia sobre São Paulo colonial, tendo como eixo aspectos inovadores da obra de Sérgio Buarque de Holanda. Analisa características de seu estilo e método, e sua influência, na produção historiográfica voltada para o estudo da economia e da população paulistas. Aborda ainda, aspectos da mentalidade do colonizador paulista, presentes em Visão do Paraíso e em outros estudos do autor referentes a São Paulo.

Na vasta produção historiográfica sobre São Paulo Colonial, poucos são os estudos dedicados aos primeiros séculos, quando a região ainda não se desenvolvia nos mesmos moldes das áreas de economia de exportação. Grande parte dos trabalhos reforça a visão da pobreza e paralisia econômica pregada pela historiografia clássica, destacando o heroísmo dos bandeirantes, como resultado da obstinação e bravura do paulista.

Já os trabalhos de Sérgio Buarque de Holanda, propuseram nova abordagem do período, voltando-se para os homens comuns, buscando recuperar seu cotidiano.

Ao tomarmos suas obras como parâmetro para nossas reflexões, pretendemos apontar as inovações nelas contidas e, também, analisar como tais questões foram tratadas na produção historiográfica sobre São Paulo.

Iniciamos este ensaio com considerações teóricas sobre seu estilo e método para, em seguida, discutir suas diferentes abordagens da organização econômica

1 Pós-graduanda em História Social. Departamento de História, FFLCH/USP. 
CHASSOT, Walkiria Costa Fucilli. Sergio Buarque de Holanda e a historiografia paulista.

e da população de São Paulo. Por fim, apontamos algumas características da mentalidade do colonizador paulista, que foram analisadas por Sérgio Buarque de Holanda em vários de seus discursos.

Com Raizes do Brasil (1936), Sérgio Buarque de Holanda introduziu o que seria a marca do conjunto de sua obra: a busca da singularidade, tanto nas características próprias ao fato, como em cada conjuntura do tempo histórico, sem nunca perder de vista o presente. Daí a ligação que Maria Odila Leite da Silva Dias, faz do modo de trabalhar de Sérgio Buarque de Holanda, com o historismo alemão ... "pelo qual o historiador enquanto homem de seu tempo tornava-se observador participante dos valores de outras épocas ... Os principais objetivos do historiador eram, a seu ver, discenir tendências, movimentos significativos, apreender "fatores determinantes", "tendências contrastantes", "forças desintegradoras", "forças vivas e estimulantes"; caberia ao historiador contemplar e observá-los, porém, jamais definir ou esquematizar ${ }^{2}$.

Sérgio Buarque de Holanda apontava, também, para certa independência criadora do historiador. Pensar a História do Brasil, sem preconceitos ou determinismos de qualquer espécie, sair da parte para o todo, postura presente em seu estilo repleto de detalhes, sem permitir que, no entanto, o conteúdo perdesse de vista o global:

"Não pretende esta ser uma historia "total": ainda que fazendo cair o acento sobre as idéias ou mitos, não fica excluida, entretanto uma consideração, ao menos implícita, de seu complemento ou suporte "material", daquilo em suma que, na linguagem marxista, se poderia chamar de infraestrutura. Mas até mesmo entre os teoricos marxistas vem sendo de há muito denunciado o tratamento primário e simplificador das relações entre base $e$ superestrutura, que consiste em apresenta-las sob a forma de uma

2 DIAS, Maria Odila Leite da Silva org. Sérgio Buarque de Holanda - Historiador. São Paulo: Ática, 1985. p.21. (Coleção Grandes Cientistas Sociais, n.51). Abrangente análise que serviu de base para este ensaio. 
influência unilateral, eliminadas, assim quaisquer possibilidades de ação recíproca ${ }^{\prime 3}$.

A partir daí - se concordarmos que o conhecimento é momentâneo, que inexistem premissas universais, que há uma "cultura de resistência que leva a captar no cotidiano as tensões e as mudanças forjando caminhos que sobrevivem a sua época; poderíamos pensar a história do cotidiano, voltada para a História das mentalidades, como aquela que nega o "herói" e recupera o homem comum, não como exceção, mas como parcela da população, mantida nas sombras; se concordamos ainda que, cabe ao historiador, articular os valores culturais e os fatores econômicos, em uma determinada época, reconhecendo-lhes as circunstâncias de tempo e de espaço, torna-se necessário criar conceitos adequados para interpretá-los. Nesse sentido é possível pensar a obra de Sérgio Buarque de Holanda, dentro do quadro do historismo, capaz de encontrar um modo de expressar o linguajar adequado para apreender dois momentos: o da época estudada e aquele do historiador.

Mas, não é o caso de definir ou rotular a obra de Sérgio Buarque de Holanda, procedimento avesso ao próprio autor. Tentamos apenas pensar as características de sua obra e o que podemos resgatar de sua coritribuição para a historiografia de São Paulo. Em seus trabalhos há o esforço de reconstruir o dia a dia dos homens comuns; atenta para não se deixar enredar em seus próprios conceitos contemporâneos, para refazer, a partir dos resquícios presentes nos documentos, a época estudada.

Podemos falar da sua proximidade com a história do cotidiano, desde que a entendamos como postura do historiador, não como escola, nem tampouco uma história de especificidades de pormenores fora de um contexto mais amplo, onde persiste a ausência de inter-relações, já que a produção histórica de Sérgio Buarque de Holanda é repleta de detalhes, de fragmentos interligados, com a função precípua de refazer os movimentos do homem e seu cotidiano.

3 HOLANDA, Sérgio Buarque de. Visão do Paraíso. 2 $2^{\text {a }}$ Ed. rev. e an p. Sâo Paulo: EDUSP/Nacional, 1969, prefácio à $2^{n}$ ed, p. XIX/XX. 
Por isso, o que sobressai em Sérgio Buarque de Holanda, é sua preocupação com a linguagem, o que, por si só, retrata sua postura frente a história. Sua marca preponderante está no estilo elaborado minuciosamente, buscando a reconstituição do espírito da época, através da adequação da linguagem. Utilizada como meio de transportar-nos para a época estudada, devolvendo-nos o "diálogo" com o tempo passado ${ }^{4}$.

De certa forma, a relação de Sérgio Buarque de Holanda com a linguagem, apresenta afinidades com a de Bakhtin, na medida que para ambos, no conhecimento histórico é fundamental o domínio dos conceitos, dos códigos da época. Em Bakhtin, linguagem e sociedade formam uma "entidade", pois todas as manifestações do homem e de sua existência, se exteriorizam e/ou se esclarecem pela palavra. Sérgio Buarque de Holanda, buscando um equilíbrio entre palavra e conceito, através da linguagem, das fontes históricas, construía uma nova linguagem contemporânea do historiador.

Para Bakhtin as formas de sensibilidade coletiva representam uma complexa relação dialética denominada "visão de mundo". Não são, portanto, nem decorrentes, nem explicáveis a partir simplesmente de estruturas econômicas ou necessidades biológicas.

Essa mesma concepção se percebe em Sérgio Buarque de Holanda aliada ao cuidado em não adotar uma única linha teórica ou intelectualista de pensamento mostrando-se contrário a tudo que pudesse tolher o historiador no seu ofício. No entanto, o "jogo dialético", é parte integrante de seu estilo e de seu método 5 .

Sérgio Buarque de Holanda, autor de rica e densa obra, erudita e instigante, revela, a cada momento, suas opçóes de historiador: a abertura de caminhos a serem trilhados, descobertos, refeitos, e mais ...

"diria efetivamente que uma das missões do historiador, desde que se interesse nas coisas de seu tempo - mas em caso contrário ainda se pode chamar historiador? - consiste em procurar afugentar do presente os demônios da História" ${ }^{\prime 6}$.

4 DIAS, Maria Odila Silva, eb cit.

5 Como expressa M. Odila Leite da Silva Dias: "O princípio dialético aparece então trabalhado no próprio estilo narrativo e entranhado na concepção do fluir do tempo e no movimento das tensóes e das forças contraditórias que ele deslinda, como em Monções e sobretudo em Visão do Paraíso". (Op. cit, p. 24)

6 HOLANDA, Sérgio Buarque de. Visão do Paraíso. pref́́cio à $2^{\text {a }}$ Ed. p. XIII. 
A forma de sua obra e a opção teórica, caminham juntas: de um lado, através da narrativa, requintada e minuciosa, traça a sinuosidade do percurso dos homens do passado; de outro, faz da história e do percurso a ser trilhado, a busca de caminhos nunca lineares e que não estão dados.

Talvez por isso, a cada leitura, reconhecemos algo de novo, temos outra revelação, não só pela abrangência de seu trabalho mas, pela atualidade de seu método, que por certo, apresenta muitas congruências com algumas linhas traçadas pela nova história, principalmente no que se refere à linguagem, ao documento, e a relação tempo estudado/tempo do historiador. Temas, atualmente muito discutidos no Brasil, já há muito estavam expressos na obra de Sérgio Buarque de Holanda na qual, a narrativa é a reconstituição do tempo, das características de uma época a partir das fontes históricas; o historiador quer adequar sua contemporaneidade à reconstrução da consciência do homens do passado.

Por tudo isso, é difícil compreeender esse "abandono", ao qual sua obra parece ter sido relegada, dentro da moderna historiografia brasileira, apesar dos caminhos abertos por sua produção, principalmente no que se refere à história paulista, objeto deste estudo.

"O próprio do historiador não está em querer ver $e$ enaltecer o passado no presente ou vice-versa, mas em reconhecer e estimar as formas diferentes que se sucedem através dos tempos. Conservar, restaurar, procurar entender o patrimônio histórico de cada povo é, sem dúvida, uma das grandes e gratas missões do historiador. Refazer, porém o presente, nos moldes do passado, de um passado que escolhemos e arbitrariamente isolamos para convertê-lo em norma insistente, é contrariar e é trair essa missão" ${ }^{\prime 7}$.

Ao pensarmos em História de São Paulo, dois trabalhos de Sérgio Buarque de Holanda - "Expansão Paulista em fins do séc. XVI e princípio do XVII" e

7 HOLANDA, Sérgio Buarque de. O Senso do Passado. Revista do Brasil. Rio de Janeiro: Rioarte-Fundaçâo Rio, n. 6, 1987, p.83. 
"Movimentos da População em São Paulo no séc. XVIII" ${ }^{8}$ - mostram os veios, por ele seguidos, na busca da compreensão da luta pela sobrevivência da população de São Paulo e sua visão de mundo. Apesar de sua abrangência e importancia, esses trabalhos nem sempre foram devidamente explorados pela historiografia. É preciso frisar que Sérgio Buarque de Holanda não relega a estrutura mas, a engendra ao cotidiano, de forma a esmiuçar-lhe as especificidades temporais. Está preocupado com o singular da história de São Paulo e é a partir dessas singularidades que constrói o quadro sócio-econômico mais amplo. Em sua obra, as estruturas mais gerais não são construções apriorísticas, mas construções urdidas no cotidiano. Volta-se inclusive para o sentimento da população, para estados de espírito, mesmo ao tratar de aspectos econômicos, (evidenciando sua proximidade com a história das mentalidades) como podemos perceber no seguinte exemplo.

"...A reabertura desse velho caminho deve ter repercutido fundamente no ânimo dos moradores de São Paulo. ... Já agora não havia meios humanos que detivessem, como tinham detido meio século antes, a um movimento imposto pelas necessidades mais imperiosas $e$ rudimentares de uma população que lutava contra a solidão $e$ a penúria $^{\prime \prime}$.

É precisamente esse recurso ao pormenor, esse importar-se com a forma como os fatores econômicos, atingem a vida cotidiana do homem comum e suas manifestações, que falta em boa parte da historiografia paulista. Nesses estudos prepondera a preocupação constante em analisar São Paulo sob a ótica da economia de exportação, talvez, também por essa razão, poucos se voltem para os primeiros séculos de história.

Entre os historiadores que se preocuparam com os séculos XVI/XVII, domina a visão de São Paulo, como uma região que sobreviveu ao isolamento e

HOLANDA, Sérgio Buarque de. A expansâo paulista do século XVI e começo do século XVII. Boletim da Faculdade de Ciências Econômicas da USP; Sérgio Buarque de Holanda. Movimentos da populaçâo em São Paulo no século XVIII. Revista do Instituto de Estudos Brasileiros v. 1, 55-111, 1966. Obs.: nome correto desse texto Movimentos de população em São Paulo no século XVII. Trata-se do mesmo texto. HOLANDA, Sérgio Buarque de. Ibidem, p. 20. 
à pobreza, numa esmaecida e "incontestável" economia de subsistência, gerada, quase sempre, por fatores externos à vontade humana, tais como as imposiçóes geográficas, etc. Por não participarem diretamente da economia de exportação, os paulistas se viam atirados ao sertão à procura de índios, metais e pedras preciosas.

Essa forma rigorosa de qualificar a economia paulista, em geral, presa, a conceitos muito influenciados, por características do Nordeste exportador é, certamente, o caminho inverso daquele trilhado por Sérgio Buarque de Holanda, na sua busca da singularidade. Não se limita á situação "marginal" de São Paulo, nem a conceitos pré-estabelecidos pela comparação com a economia de exportação; instiga-o exatamente o que é próprio da região, o distinto, o que a torna elemento vivo e dinâmico, a contraposição frente ao estabelecido "a priori", como na seguinte passagem de Monçôes:

"A sociedade constituída no planalto da C'apitania de Martim Afonso, mantem-se por longo tempo ainda, numa situação de instabilidade ou de imaturidade que deixa margem ao maior intercurso dos adventícios com a população nativa. Sua vocação estaria no caminho, que convida ao movimento, não na grande propriedade rural, que cria indivíduos sedentários. ${ }^{10}$

Em seus trabalhos sobre São Paulo, constrói a narrativa partindo das tensões inerentes à realidade sócio-econômica mostrando, por exemplo, como as tentativas centralizadoras, que buscavam cercear a autonomia paulista criavam, ao contrário, reações mais libertárias por parte dos colonos.

Por caminhos semelhantes, em sua obra Formação do Brasil Contemporâneo (1942), a qual Sérgio Buarque de Holanda se refere como "uma recente e lúcida análise" ${ }^{11}$, Caio Prado Jr. traça um amplo painel do período colonial. É comum entre os dois autores o entretecer de elementos, aparentemente pouco importantes, para mostrar através de uma construção sutíl todos os meandros do tempo estudado.

10 HOLANDA, Sérgio Buarque de. Monçöes. $2^{\circ}$ ed. São Paulo: Alfa-Omega, 1976.

11 PRADO JR., Caio..Formação do Brasil Contemporâneo (Colonial). $1^{\text {a }}$ Ed. São Paulo: Martins, 1942. A referida citação de Sérgio Buarque encontra-se em Monções, p.72. 
O ponto central desse trabalho de Caio Prado Jr., é o "sentido" que ele busca no conjunto do Brasil colônia. O elemento norteador é o "sentido da colonização", ou seja, "fornecer gêneros tropicais ao mercado externo" ${ }^{12}$. Não utiliza o conceito de forma determinista, ao contrário, entende-o como resultado de uma visão mais ampla:

"Todo povo tem sua evolução, vista à distância, um certo "sentido". Este se percebe não nos pormenores de sua História, mas no conjunto dos fatos e acontecimentos essenciais que a constituem num largo período de tempo" ${ }^{13}$.

Utiliza-o como eixo, para justificar o processo de formação da sociedade dos três séculos de Colônia, porém não restringe sua análise a isso. Estuda detalhadamente, todas as regiões do país, mesmo as que não estão engajadas nesse "sentido", buscando em cada uma delas seu processo peculiar.

Outro ponto comum entre Sérgio Buarque de Holanda e Caio Prado Jr., é o de realizarem suas análises sem cerceá-las por nenhum limite, fugindo a determinismos econômicos ou políticos. Por isso, pensamos ser resultado de interpretações equivocadas, os trabalhos que, embasados em Caio Prado, acabam por estabelecer a economia de exportação como parâmetro para suas análises sobre São Paulo.

Para Caio Prado Jr. o que distingue a economia de exportação da economia de subsistência é o objetivo primário de cada uma, já que na maior parte do território elas acabam por conviver, uma em estreita relação com a outra. É inegável sua influência nos trabalhos sobre a história paulista, mas alguns, parecem ignorar a dinâmica de sua análise e vêem no autor uma determinação estrutural, que não resiste a uma leitura mais atenta.

Se, em Formação do Brasil Contemporâneo, Caio Prado não faz uma análise específica de São Paulo, insere aspectos de sua realidade social e econômica em vários capítulos. E, em momento algum, define a economia

12 PRADO JR., Caio.Ibidem, p.25.

13 PRADO JR., Caio. Ibidem,p. 13. 
paulista como sendo meramente de subsistência, ao contrário, descreve-a de forma aberta:

"... o caso particular e especial de São Paulo, mais precisamente do Planalto Paulista... Zona de passagem, São Paulo não chegou a formar, no período Colonial, vida propria: a pequena mineração de lavagem que ai se praticou nos dois primeiros séculos, a insignificante agricultura ensaiada, de caráter puramente local, não tiveram expressão alguma. As grandes fontes da vida paulista serão o comércio de escravos indígenas...; comércio de gado...e quando se descobre o ouro em Minas Gerais, São Paulo será por algum tempo a única ou principal via de acesso..." ${ }^{14}$.

A flexibilidade dessa obra não foi, no entanto, completamente compreendida, o que gerou uma tendência a sua esquematização, acentuada em obras que dão ênfase ao econômico e, que, por isso, acabam por levar a história de São Paulo a um esvaziamento, como que transportando sua "pobreza" econômica para sua história.

Parcela significativa dos textos de história econômica restringem-se ao econômico, sem reconstruir as relações com o cotidiano da época em questão, ou seja, relegam aquilo que tanto para Caio Prado, como para Sérgio Buarque de Holanda era fundamental: realizar uma reconstituição mais abrangente da conjuntura econômica sem, no entanto, perder de vista suas mediações sociais, como está explícito no seguinte trecho de Esboços dos Fundamentos da Teoria Econômica":

"E se a economia política se ocupa propriamente dos fatos e a historia econômica da sucessão daqueles fatos, e pois, do processamento dessa sucessão, é certo também que nem a economia política pode esquecer e desprezar o processo imanente em todo o fato $e$ que tende permanentemente a lhe transformar o conteúdo, nem tampouco a história econômica pode ignorar a natureza intima e a

14 PRADO JR., Caio. Ibidem,p. 61. 
estrutura orgânica dos fatos que compõem os processos de que ela se ocupa $^{15}$.

Para ressaltarmos o papel secundário em que as regiões entendidas como de subsistência tem sido colocadas dentro da historiografia brasileira - situação evidenciada não só pela pequena quantidade de trabalhos como também, pelo tipo de abordagem dada ao tema, analisaremos alguns aspectos da importante produção de Alice P. Canabrava. Em seus estudos dedicados a São Paulo, ateve-se fundamentalmente ao período da economia de exportação, o que não diminue sua inegável contribuição para a compreensão de nossa história, mas reafirma a situaçào que apontamos acima e serve-nos como exemplo dessa história econômica, pouco afeita às questões do cotidiano, o que podemos perceber quando expressa o objetivo de seu trabalho Terras e Escravos na Grande Lavoura Paulista:

"...abordamos o problema da área da propriedade rural na Capitania Paulista, dedicada às culturas de exportação, essencialmente o açúcar e o café... Partimos da hipótese de que as tendências indicadas pela relação terra/escravos, poderiam instruir a noção quantitativa, no momento histórico, com referência as propriedades rurais dedicadas às culturas de exportação, ou seja, a grande lavoura" ${ }^{16}$.

Podemos perceber, que ao contrário dos caminhos abertos por Sérgio Buarque de Holanda, por exemplo, em "Movimentos da População em São Paulo no séc. XVII", onde "procura explicações para o nomadismo paulista nas condições da vida material"17 $\mathrm{e}$, por Caio Prado Jr., que desce aos meandros do conjunto da estrutura econômica-social, essa abordagem da história econômica não utiliza os dados como meio para compreender a vida da regiáo em sua

15 PRADO JR., Caio. Esboço dos fundamentos dá Teoria Econômica. São Paulo: Brasiliense, 1957. p.10.

16 CANABRAVA, Alice P. Terras e escravos na Grande Lavoura Paulista. Anais do Simpósio da ANPUH. São Paulo. v.VIII, 1976. Os grifos na citação são nossos.

17 DIAS, Maria Odila L. S. Op.cit..p. 42. 
globalidade, mas como fim em si mesmo, empenhada que está na compreensão exclusiva do processo da vida econômica.

A leitura do texto de A. P. Canabrava, no trecho em que trata a questão das sesmarias, inclusive citando Caio Prado, evidencia essa diferença. Enquanto este inclui a mentalidade do colonizador português na explicação da adoção da grande propriedade, Canabrava não demonstra preocupação com os fatores formadores da grande propriedade mas, com as dimensões espaciais, a área da sesmaria. Quanto ao fator humano, estaria inclú́do para ela, em "outras variáveis"18.

Em obra recente, Zélia Maria Cardoso de Mello, de certa forma mostra uma abertura para esses caminhos, presentes nas obras de Sérgio B. de Holanda e Caio Prado Jr., mesmo que características da história econômica tradicional permaneçam marcantes. Em Metamorfoses da Riqueza em São Paulo 1845/1895, percebe-se a tendência a "humanizar" o tratamento dos dados econômicos, em trechos como esse:

"As condições sócio-econômicas se refletem de alguma maneira na riqueza dos indivíduos, assim como as transformações em curso. O modo como se compóe o "portfólio" dos individuos encontra-se em móveis, animais, enfim, variados tipos de bens, e sua participação na riqueza total deve refletir não só as características da sociedade, mas alguns de seus movimentos" ${ }^{19}$.

Utiliza a idéia do "sentido da colonização" mas, a medida que se volta para a economia paulista dos primeiros séculos, entende-a como desarticulada da economia colonial. Propõe a discussão da riqueza, sem especificar quais as fronteiras entre riqueza e pobreza e, esclarecer em que medida mantém como parâmetro as características das áreas de exportação. Quando rapidamente, analisa os primórdios paulistas conclui de forma tradicional:

18 CANABRAVA, Alice P. Op. cit..p.890.

19 MELLO, Zélia Cardoso de. Metamorfoses da Riqueza. São Paulo, 1845-1895. $1^{\text {a } . ~ S a ̃ o ~}$ Paulo: HUCITEC, 1985. p.28. 
"Antes o que se vê é o retrato da pobreza... bens para auto-consumo, economia não monetária, presença de escambo... Os emprestadores tinham papel importante na economia e registram-se nos inventários "negros e mulatos da terra" ${ }^{20}$.

Por outro lado, mais recentemente, algumas obras tem realizado a crítica a esse tipo de abordagem e tem redescoberto caminhos, alguns dos quais, característicos de Sérgio Buarque de Holanda.

John D. French, além da crítica a essa visão tradicional, aponta para o caminho que busca, na economia paulista, suas peculiaridades e propõe uma análise que não parta dos pressupostos gerados pela comparação com a rica economia do açúcar no Nordeste brasileiro, argumentando que

"As mudanças econômicas ocorridas em São Paulo, em seus primeiros anos, passaram despercebidas, já que era difícil vislumbrar qualquer tipo de crescimento, estagnação ou declínio. Há uma aparência superficial de continuidade em economias orientadas para a subsistência, e uma falta de indicadores dramáticos do nível de atividade econômica. $\dot{E}$ fácil assumir, incorretamente, que a realidade em consideração é estática e imutável. Por essas razões os historiadores tem tido dificuldade em compreender a dinâmica da economia de São Paulo colonial, ou o papel que desempenharam as bandeiras neste processo" ${ }^{21}$.

Há no artigo em questão, uma preocupação expressa de compreensão das comunidades agrícolas de subsistência, segundo o autor, tema "abandonado" pela historiografia brasileira.

Interessado em como se dá a acumulação, que vai gerar a riqueza, e também em como ela se distribui, antes e depois, do crescimento da economia de mercado em São Paulo, "encorajada pela economia colonial, da qual São Paulo fazia parte" ${ }^{22}$, John French contrapõe-se ao enfoque da historiografia tradicional que

20 MELLO, Zélia Cardoso de. Ibidem. p. 42.

21 FRENCH, John D. Riqueza, poder e mão-de-obra numa Economia de Subsistência: São Paulo, 1596-1625. Revista do Arquivo Municipal. São Paulo, v. 45, n. 195, 1950 p.79.

FRENC.H, John D. Op. cit., p. 80. 
assumiu a produção para subsistência como insignificante e estática. Volta-se para os primórdios de São Paulo para "capturar a realidade de movimento e mudança".

A questão da busca do singular, do movimento, sem desprezar os dados da estrutura econômica, desenvolvidos por Sérgio Buarque de Holanda são também resgatados por Janice Teodoro da Silva, em São Paulo 1554/1880. Discurso Ideológico e Organização Espacial.

$\mathrm{Na}$ exposição dos objetivos do trabalho está implícita uma crítica ao enfoque dado pela história econômica convencional na qual "os fenômenos e processos urbanísticos, aparecem como decorrências mecânicas das transformações infra-estruturais" ${ }^{23}$. Opta por uma "análise (por assim dizer) interna desse processo, a partir de indicações contidas no discurso sobre a cidade produzido pela Câmara de São Paulo. Ou seja, quais as idéias de cidade que presidiram os diferentes momentos..." ${ }^{24}$.

Percebe-se que Janice Theodoro da Silva procura, através da mentalidade e do cotidiano apreendidos dos documentos, resgatar o peculiar do desenvolvimento urbano, sem ater-se às estruturas apriorísticas.

Ao citar Caio Prado Jr: "Para se compreender a administração colonial é preciso, antes de mais nada, desfazer-se de muitas noções que já se tornaram em nossos dias verdadeiros prejuízos" -, ${ }^{25}$ mostra, não só os caminhos de sua análise, como também nos recorda outra semelhança entre Caio Prado e Sérgio Buarque de Holanda, ou seja, a preocupação com os conceitos, presentes nas fontes e expressos pelo historiador.

Já acentuamos ter Sérgio Buarque de Holanda, em sua obra, evitado o geral e o determinista buscando, em seu objeto, o específico, que nasce da interação do econômico, do social e do cultural, em cada lugar e época. Daí a riqueza de seus trabalhos sobre São Paulo, dando relevo às características peculiares de sua vida material, ao embate longo e difícil dos paulistas na Colônia.

23 SILVA, Janice T. Ja. Săo Paulo 1554-1880. Discurso Ideologico e Organizaçäo Espacial. 1" ed.. Sẩo Paulo: Moderna, 1984, p.9.

25 Sua postura em relação a Caio Prado encontra-se em Op. cit., p. 18. 
CHASSOT, Walkiria Costa Fucilli. Sergio Buarque de Holanda e a historiografia paulista.

Da mesma forma que apresenta novos enfoques para a construção da história econômica de São Paulo, também, em relação à população, percorre caminhos diferentes daqueles que vêem a história paulista determinada pelo nomadismo e pelo espírito aventureiro, como se fossem causas das flutuações demográficas, e não, derivadas da luta pela sobrevivência ${ }^{26}$. À visão tradicional, onde a populaçáo paulista aparece como pobre, e sempre em via de extinguir-se, contrapõe uma população cujo movimento de ir e vir gera novas povoações, cria novos caminhos, soluciona crises econômicas e sociais.

Para Sérgio Buarque de Holanda, população é tema abrangente e instigante: comporta tensões, acomodações, movimento. Em seu estudo, não é a números, apenas, que se reporta, nem restringe sua análise a grupos sociais. É o todo, a dinâmica social que se impõe como real objeto de estudo. É o que Maria Odila entendeu como "traço renovador" "o esforço de reconstituir a vida dos homens anônimos e o sistema de dominação a que viviam expostos" ${ }^{27}$. Recupera, não só nos escritos relativos a São Paulo, mas também em obras como Visão do Paraíso, o estudo das mentalidades dos homens comuns, ausentes em nossa produção historiográfica.

Em sua narrativa, forças contrárias se enfrentam, o moderno e o tradicional se embatem, gerando o novo, assim através desse recurso constante aos "pormenores descritivos que compõe forças, movimentos, mudanças de mentalidade" 28 , marca seu estilo. No estudo da população paulista, volta-se para fatores endógenos, sem ater-se apenas àqueles tradicionalmente evocados (índios, autonomia, nomadismo), ao preocupar-se com o cotidiano, traz a cena, as fugas da justiça, da Igreja e dos impostos que, aliados a outros aspectos constituem o singular, analisado por exemplo, em "Movimentos da População" onde diz:

Sobre esses aspectos ver: BLAJ, Llana. Pulsaçöes, sangrias e sedimentação: Sérgio Buarque de Holanda e a análise da sociedade paulista no séc. XVII. Sérgio Buarque de Holanda: Vida e Obra. São Paulo: IEB-USP, 1988, p.83/85.

28 DIAS, Maria Odila Leite Silva. Op. cit., p. 26. 
"Nas capitanias paulistanas a expansão do povoamento processou-se durante longo tempo segundo, moldes que não encontram quase paralelo pela mesma época, em outros lugares da América Portuguesa" ${ }^{29}$

Ao pesquisar a sociedade paulista buscava, inclusive através de dados demográficos, a compreensão para a mobilidade da população, considerando, não só, seu setor orgânico, mas os "párias", que viviam à margem da sociedade estabelecida (sob as regras da Coroa e da Igreja) e não apenas constituiam a imensa maioria, somando-se a eles a mão-de-obra-indígena, mas na visão do autor, ocuparam papel de destaque na formação das características da população e da sociedade paulistas ${ }^{30}$. Está preocupado em mostrar as interações entre grupo, meio e heranças culturais, que explicam a própria natureza do povoamento paulista, o que para Antonio Cândido, torna seus estudos "os mais sólidos e penetrantes sobre o ajustamento do colonizador ao meio físico da América" ${ }^{31} \mathrm{e}$ para quem a compreensão do processo da expansão da população e da sociedade, que se formou em São Paulo entre os séc. XVI a XVIII, passa pela seguinte reflexão de Sérgio Buarque de Holanda:

"Para a análise histórica das influências que podem transformar os modos de vida de uma sociedade é preciso nunca perder de vista a presença, no interior do corpo social, de fatores que ajudam a admitir ou a rejeitar a intrusão de hábitos, condutas, técnicas e instituições estranhos à sua herança de cultura; longe de representarem aglomerados inânimes e aluviais, sem defesa contra sugestöes ou imposiçōes externas, as sociedades, inclusive e sobretudo entre povos naturais, dispõem normalmente de forças

29 HOLANDA, Sérgio Buarque de. Op. cit., p. 55, n. 9. V. tbem BLAJ, Ilana. Op. cit.,

30 A respeito da análise dá sociedade e sua divisâo em setor orgânico e inorgânico, ver PRADO JR., CAIO em Formação do Brasil Contemporâneo, a partir da p.281. Em Monçöes, p.71/72, Sérgio Buarque de Holanda, demonstra sua concordância com a análise af exposta.

31 CANDIDO, Antonio. Os Parceiros do Rio Bonito. $5^{\circ}$ ed. Sâo Paulo: Duas cidades, 1979. p. 36. 
CHASSOT, Walkiria Costa Fucilli. Sergio Buarque de Holanda e a historiografia paulista.

seletivas que agem em benefício de sua unidade orgânica, preservando as novas aquisições até ao ponto em que se integrem na estrutura tradicional ${ }^{32}$.

Essa característica do autor em realizar sua análise histórica considerando vários aspectos dinâmicos do processo social, nos leva a refletir sobre alguns autores que, hoje, trilham esse caminho. Janice T. da Silva, em texto anteriormente citado, realiza um estudo minucioso da mentalidade da época, recorrendo constantemente ao recurso dos historiadores que "deixam o documento falar" ${ }^{33}$. Esse elemento de seu estilo, denota a preocupação em entender a estrutura mental do colonizador, adequada à colonização e sua influência no decorrer do tempo. Recorre ao discurso ideológico visando as formas de organização espacial em São Paulo, preocupada sempre em estabelecer a relação meio-culıura-sociedade, o que está expresso em sua perspectiva teórica:

"...concordamos amplamente com Eliseo Verón, quando demonstra que os sistemas de representações "constituem uma dimensão central das próprias condições materiais, não são outra coisa que relações sociais" ${ }^{34}$.

Exemplo significativo, encontra-se na dissertação apresentada por John M. Monteiro em 1985, onde há uma crítica à historiografia referente a São Paulo, que complementa e corrobora aquela por nós aqui exposta. Indica a presença de uma visão oficial, estandartizada da história de São Paulo, baseada nos textos de Afonso de Taunay e Alfredo Ellis, mostrando que, mesmo em textos mais recentes que questionam essa visão, ela se faz presente ${ }^{35}$. Preocupa-se com a

32 CANDIDO, Antonio. Op. cit., p. 37.

33 SILVA, Janice T. Op. cit., p. 12.

34 A referência feita por Janice T. da Silva diz respeito ao texto de Eliseo Verón. Ideologia, estrutura, comunicação.

35 Referimo-nos à tese apresentada em 1985, por John M. Monteiro, SÄO PAULO no Século XVII: Economia e Sociedade. A afirmação mencionada, encontra-se na p.II (Citaçấo p.V). 
compreensão da história de São Paulo dentro de suas circunstâncias próprias, buscando reconstituir o efetivo papel dos índios, do trabalho indígena, na formação da riqueza e da sociedade paulistas. Busca nas relações entre colonizador e indígena as tensões e acomodações que as caracterizaram. Procura resgatar àquela São Paulo jovem e "marginal", a parcela da população, esta sim marginalizada, e é nela que busca as raízes da situação paulista durante os primeiros séculos ${ }^{36}$.

Temos ressaltado o interesse de Sérgio Buarque de Holanda em estudar o dinamismo da população paulista, tanto em seu aspecto demográfico, quanto no da expansão geográfica. Inova, mais uma vez, a medida que mostra a importância dos aspectos demográficos, como meio de atingir a compreensão das estruturas sociais e econômicas, e acaba por estimular, a partir de 1960, o crescimento da História demográfica ${ }^{37}$.

Como modelo dessa História demográfica, recorremos à obra pioneira de Maria Luiza Marcílio, A Cidade de São Paulo-Povoamento e População $1750 / 1850$, na qual constrói primeiramente, um painel das características geográficas e suas influências na formação, organização e crescimento da cidade, sem entretanto, fugir à visão tradicional da região pobre e isolada de certo modo, mantendo como parâmetro as regióes representativas dos anseios da Metrópole. Em seguida, faz uma apresentação analítica das fontes e técnicas utilizadas, para na última parte, baseada nos dados obtidos nas séries de Registros Paroquiais e nos Recenseamentos, fazer uma análise da população paulista.

Apesar de ter contribuído com uma série de dados, que acabaram por enriquecer outras análises e de oferecer uma ampla visão, em termos numéricos,

36 MONTEIRO, John. Op. cit., p.V. "Thus, the roots of rural poverty in São Paulo are to be found not only in the general lack of capital, labor, and commercial opportunity faced by the European settlers, but more specifically within the historical process that was the evolution of indian slavery in the region."

37 MESGRAVIS, Laima. Aspectos da Sociedade Paulista no Século XIX na visão de Sérgio Buarque de Holanda, in: Sérgio Buarque de Holanda: Vida e Obra. São Paulo: IEB-USP, 1988 , p.95/98. 
CHASSOT, Walkiria Costa Fucilli. Sergio Buarque de Holanda e a historiografia paulista.

da forma de vida da população, não os utiliza de modo a reconstituir o aspecto dinâmico dessa população ${ }^{38}$.

Além disso, dedica-se também ao período voltado a economia de exportação, apesar, de em termos técnicos, podermos entender porque não se dedica aos primórdios da história paulista, pois segundo Marć́lio, essa técnica torna-se difícil de ser aplicada, tanto que os estudos relativos aos séculos XVI/XVII eram (em 1968) em pequeno número e de base documental frágil ${ }^{39}$.

"Ora, assim como essas idéias se movem no espaço, há de acontecer que também viajem no tempo, e por ventura mais depressa do que os suportes, passando a reagir sobre condições diferentes que venham a encontrar ao longo do caminho" ${ }^{40}$.

Ao iniciarmos está última parte, na qual ressaltamos características da mentalidade do colonizador paulista, presentes em Visâo do Paraíso, vamos em rápida abordagem, situar a produção e a forma desta obra.

Visão do Paraíso foi escrita entre 1955/1957 como tese, visando a Cátedra de História da Civilização Brasileira, na Faculdade de Filosofia da USP; foi publicada na sua forma original em 1959, revista e ampliada em 1968 para uma

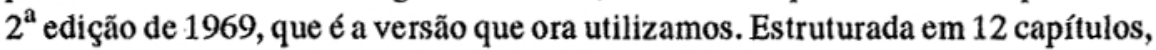

38 Florestan Fernandes em, Aspectos do povoamento de São Paulo no século XVI, faz a seguinte análise sobre o método demográfico: "...oferece uma imagem numérica bastante nítida e de fácil manipulaçâo do estado e das tendências dos processos vitais da populaçấo... Mas apresenta o inconveniente de isolar tanto o aspecto estático, como o aspecto dinâmico da população, dos fatores sociais, que a explicam e, num certo sentido a determinam." Não nega a importância do método mas propõe aliá-lo à análise morfológica que pretende "...compreender a população como realidade social. Por isso não considera a população em si mesma, mas como base e parte de um amplo sistema de relaçóes, que coloca os indivíduos em condição de se adaptarem ao meio cultural circundante, de desenvolverem e adestrarem culturalmente suas capacidades...". Rev. de Administração, FEA/SP, n.24, Maio 1948

39 MARCfllo, Maria Luiza. A Cidade de São Paulo, Provoamento e Populaçäo. $1^{\circ}$ ed. Săo Paulo: EDUSP, 1974. p. 59.

40 HOLANDA, Sérgio Buarque de. Op. cit., p. XX (prefácio). 
pode ser dividida em duas partes: num primeiro momento (até o capítulo VI) mostra a resistência dos portugueses e os mitos que apaixonam os espanhóis, considerando seus reflexos no descobrimento, conquista e exploração dos mundos novos; a partir do capítulo VII, trata da formação dos motivos edênicos, da introjeção dos mitos nos colonos e como se manifestam no período colonial. O objetivo do livro foi o de mostrar até onde, em torno da imagem do Éden,

"tal como se achava difundida na era dos descobrimentos marítimos, se podiam organizar, num esquema bastante fecundo, muitos dos fatores que presidiram à ocupação do europeu do Novo Mundo, em particular da América hispânica, mas que de certa forma tenham influido na colonização portuguesa".

Como nos diz o autor, ainda no prefácio.

Sérgio Buarque de Holanda, partindo dos escritos dos cronistas, dos colonos e marinheiros dos séculos XVI e XVII, escreve sobre a resistência dos portugueses à fantasia, opõe o seu realismo ao mito do paraíso e elabora o tema da permanência do tradicional frente ao novo. Mostra como o fatalismo marcou a visão da realidade dos portugueses, que buscavam no Brasil apenas Portugal, ou por outro lado, transformá-lo num "outro Peru".

Em São Paulo, os desejos da Metrópole e de seus representantes, acabaram por desenvolver-se, devido às condições específicas da região, de maneira mais lenta e geraram algumas atitudes, por parte dos colonizadores, difíceis de serem imaginadas em outras regiōes da Colônia, principalmente naquelas ligadas à economia de exportação. Devido às condições materiais, aqui se avivava a discussão, entre os que pregavam, serem as verdadeiras "minas" no Brasil as lavouras de açúcar e os que queriam encontrar na Colônia um outro Peru.

O sonho do "outro Peru" transferiu para a Região paulista mitos como o da Serra Resplandecente, ligado à sua proximidade com o Peru dos castelhanos. $O$ desejo de encontrar riquezas minerais, levou a se buscar em São Paulo a concretização desse sonho, devido...às entradas ao sertão e proliferarem as notícias de supostas descobertas de ouro, e também por acreditarem ser este o melhor caminho de acesso ao Peru. As condiçöes lhes pareciam tão ideais que em 1609, houve determinação governamental, para que lhamas fossem trazidas para cá, no entanto, por estas terras de Martim Afonso, o índio e as vantagens de 
CHASSOT, Walkiria Costa Fucilli. Sergio Buarque de Holanda e a historiografia paulista.

seu aprisionamento, mostravam-se muito mais seguros para a sobrevivência na região do que as "minas lendárias".

A medida que se alastravam as estórias das riquezas minerais paulistas, aumentava o afluxo de gente vinda de outras capitanias e, mais que isso, cresciam os interesses metropolitanos na região, que se manifestaram através de expediçóes organizadas para as entradas pelo sertão, que por outro lado, acabaram por incentivar as tentativas particulares, trazendo à tona duas questōes: primeiro, a preferência pela possibilidade de riqueza imediata que a mão-de-obra indígena significava e, em segundo lugar, a ameaça que a interferência da Côroa representava para a "autonomia", à qual os paulistas estavam habituados, como Sérgio Buarque de Holanda destaca em trechos como os que se seguem:

"...De preferência à prata, ao ouro e as pedras coradas, alvo principal das Bandeiras "dirigidas", não tardarão eles a volver-se para o cabedal mais seguro, mais imediato e mais consentaneo ao cabo com a rústica economia das terras do Planalto. Isto é, para a riqueza que representa a mão-de-obra indigena afeita à lavoura..."

"...A mobilização da gente do planalto visando a captura de fantásticas riquezas para a Coroa, constitui, sem dúvida, uma ameaça à vida livre e sem sujeição de quem tinha habituado, de longa data, a tamanha soltura..." ${ }^{41}$.

Poderíamos afirmar que o colono paulista ao mesmo tempo que buscava criar aqui Portugal, queria manter-se afastado do poder da Metrópole, o que se evidência não só pelo parco interesse pelas explorações oficiais, em busca das pretensas minas, a medida que sua descoberta implicaria em ter que enviar os tesouros para a Coroa, além do que, aqui se estabeleceriam presídios e tributos, e mais que isso,

"perderiam o governo quase livre que tinham de sua república, seriam mandados onde antes mandavam, e nem lhes deixariam ir ao sertão, ou se lá fossem, lhes tirariam as peças apresadas para as empregar no serviço da minas ${ }^{\prime 42}$.

41 HOLANDA, Sérgio Buarque de. Visäo do Paraiso, p. 54.

42 HOLANDA, Sérgio Buarque de. Ibidem, p. 54. 
Idéia que também está expressa em "Movimentos da população", quando o autor explica o nomadismo paulista, mostrando que um dos motivos da fuga para o sertão era afastar-se da polícia e da doutrina, para ficar "fora do alcance da justiça civil e das censuras eclesiásticas" ${ }^{43}$.

As estórias de ouro e prata em São Paulo, acabam por gerar outras, através das quais, os paulistas, mesmo achando algum minério, escondem para evitar que seus medos se concretizem.

Formou-se no paulista uma noção diferenciada de colonizador, principalmente frente àquela das regiões onde a presença da Metrópole se faz mais forte. $\mathrm{O}$ que acontece em São Paulo é resultado de fatores específicos ${ }^{44}$.

Ainda em Monções, o autor nos mostra que a lentidão com que as determinações da Metrópole se impóem em São Paulo "terá profundas consequências", pois áqui, "a ação colonizadora realiza-se por um processo de contínua adaptação a condições específicas do ambiente americano". Aqui se dá o retrocesso ao rude e primitivo, que só muito lentamente há de dobrar-se ao modo europeu. O que guia o colonizador paulista não é diretamente o mercado externo mas, a luta pela vida; impossibilitado pelas condições econômicas de, por exemplo, adquirir mão-de-obra negra, inacessível aos padrões da região, o colono lança mão do indígena que passa a constituir seu mais forte parâmetro.

O caminho traçado por Sérgio Buarque de Holanda, através dos mitos, expõe as tensões entre o arcaico e o moderno, vividas na colonização portuguesa, voltada para o "paraíso conquistado" da exploração pura e simples, enquanto, além da fronteira, a América espanhola, idealizava os sonhos e as surpresas. Às transformações sofridas pelos mitos na passagem das Indias de Castela para os domínios portugueses, o autor denomina "atenuações plausíveis".

Em São Paulo, podemos notá-las à medida que a proximidade, reforçada pela atividade econômica (gado, zona de passagem, índios) trouxe também um maior contato com os mitos castelhanos. Também marcantes são as consequências advindas do choque entre a importância da mão-de-obra indígena para os paulistas e as idéias edênicas do homem americano, do bom selvagem e também da postura jesuítica frente à escravização do índio.

O definhar dos mitos na colonização portuguesa é tema que está presente em Visão do Paraíso, através da reação aos mitos ou arquetípos que, ou

43 HOLANDA, Sérgio Buarque de. Ibidem, p. 92.

44 Como ressalta Sérgio Buarque de Holanda: "Em toda parte é idêntico o objetivo dos colonos portugueses. Diverge unicamente, ditado por cincunstâncias locais, o compasso que, num e noutro caso, dirige a marcha para esse objetivo." Monções, p.20. 
incomodavam os colonizadores, desmentidos pela própria experiência. Os exemplos seguintes mostram formas dessas atenuações, evidenciando as tensões entre idéias e prática, mito e realidade:

"...Anchieta, a servir de médico e sangrador, acrescenta que ficou incumbido de "deitar imprastos, alevantar espinhaelas, $e$ outros ofícios de albeitar, que eram necessários para aqueles cavalos, isto é aos indios". Dificilmente aqueles partidarios daquela teoria de que os antigos americanos se assemelhavam em tudo a brutos irracionais, encontraria expressão mais dura do que essa, do suave evangelizador das nossas selvas ${ }^{45}$.

"Linhas adiante, como deva aludir a certa lassidão $e$ desleixo da terra, por efeito de quentura e dos mantimentos, que deixam os homens algo tanto fracos e minguados das forças que possuem no Reino, apressa-se a ponderar, receoso, talvez, de ser acusado de contradição: "isto e enquanto as pessoas são novas na terra, mas depois que, por algum tempo, se acostumam, ficam tão rijos e bem dispostos, como se fora sua mesma pátria" ${ }^{46}$.

Em São Paulo, a idéia da Serra Resplandecente, transmuda-se frente ao minguado ouro e às teorias do bom selvagem, ficam adormecidas pelas necessidades do cotidiano, até serem despertadas no século XVIII, pela urgência da realidade dos luso-brasileiros, em transformá-lo em "uma idealidade e um símbolo".

"...E o Rio Amazonas

Que corre Trás-os-Montes

E numa Pororoca

Desagua no Tejo

Ai, está terra inda vai cumprir seu ideal

Ainda vai tornar-se um Império colonial.... ${ }^{47}$.

45 HOLANDA, Sérgio Buarque de. Visäo do Paraiso. p. 303.

46 HOLANDA, Sérgio Buarque de. Ibidem, p. 243.

47 Trecho da música de Chico Buarque de Holanda e Ruy Guerra, "Fado Tropical", parte da peça Calabar. $5^{\wedge}$ ed. Săo Paulo: Brasiliense, 1974, p.14-16. 
Sérgio Buarque de Holanda nos transporta à diversas épocas e através de visões do paraíso, leva-nos a perceber toda a complexidade da estranha geografia fantástica, criada pelo desejo dos homens e pelo seu medo do desconhecido, que gerou também monstros e estranhas criaturas. Recorrendo a mapas, itinerários e diários de viagem, apresenta-nos a concepção fantástica do mundo, que os homens, impregnados de mitos, acabam por construir; moldando o espaço, representavam a realidade e interpretavam o relato dos indígenas, segundo o que desejavam entender, influenciados por motivos arquetípicos.

A mitologia geográfica, introduzida pelo descobrimento, acentuava-se a medida que surgiam as expectativas de tesouros, em São Paulo. As iniciativas oficiais para a descoberta de minas preciosas, provocou aqui uma invasão de "imagens mirificas", de vastas lagoas ou montanhas de diamantes, e de novos caminhos possíveis ou imaginários ${ }^{48}$.

"Todas essas aparentes precisões e clarezas lançadas sobre coisa tão turva, provinham de uma conviç̧ão originada até certo ponto em dados reais ou posstiveis. Por outro lado não deixavam elas de comportar elementos fantásticos, que um lento processo de sedimentação lhes agregara no fio dos anos ${ }^{49}$.

ABSTRACT: The present essay discusses aspects of the state of São Paulo historiography on colonial times based on the innovative writings of Sergio Buarque de Holanda. The author analyses his style and method and his influence on the historiography of the economy and population of the state of Săo Paulo. The article also deals with colonial mentality as introduced in Visäo do Paraiso and other studies of the same historian.

48 Sobre esse tema ver Visão do Paraiso, Cap. IV, principalmente p. 98.

49 HOLANDA, Sérgio Buarque de. Ibidem, p. 57 